Cordovil, J.C.S.; Cebuliski, B.S.P.; Costa, W.L.; Nunes, P.B. Políticas públicas, atividade turística e estratégias de desenvolvimento: uma abordagem sobre o turismo em Altamira (PA). Revista Brasileira de Ecoturismo, São Paulo, v.6, n.5, nov-2013/jan-2014, pp.850861.

\title{
Políticas públicas, atividade turística e estratégias de desenvolvimento: uma abordagem sobre o turismo em Altamira (PA)
}

\author{
Public policy and tourist activity development strategies: a focus on \\ tourism In Altamira (PA, Brazil)
}

\section{José Carlos da Silva Cordovil, Bruna Suelen Pereira Cebuliski, Wagner Lima Costa, Patrícia Barbosa Nunes}

\begin{abstract}
RESUMO
O turismo se apresenta no contexto atual como uma das mais pujantes atividades econômicas, e por consequência uma relevante estratégia de desenvolvimento. Como pratica social provoca repercussões espaciais pelas relações que são engendradas. Nestes termos, o presente artigo aborda a crescente importância do turismo como estratégia de gestão para o desenvolvimento a partir das ações deliberadas no âmbito do poder público para o incremento da atividade. O trabalho tem como foco de análise as ações de incentivo ao turismo em Altamira no Estado do Pará, procurando evidenciar especialmente as políticas planejadas, por meio de um conjunto de documentos oficiais, que visam ao fomento da atividade. Como procedimento metodológico foi realizado, o levantamento e análise documental, além da pesquisa e análise bibliográfica da produção que trata das políticas de turismo para a Amazônia, Estado do Pará e, por conseguinte à Altamira. Feita a organização e sistematização dos dados coletados evidencia-se as políticas de desenvolvimento do turismo em Altamira e sua relação especial com o discurso do desenvolvimento sustentável de onde emerge as políticas de incentivo ao ecoturismo.
\end{abstract}

PALAVRAS-CHAVE: Políticas de Turismo; Desenvolvimento; Ecoturismo; Amazônia; Altamira.

\begin{abstract}
The tour is presented in the current context as one of the most vigorous economic activity, and therefore a significant development strategy. As a practicing social causes spatial repercussions for relations that are engendered. Accordingly, this article addresses the growing importance of tourism as a management strategy for the development from the deliberate actions on the part of the government to increase the activity. The work focuses on the analysis of actions to encourage tourism in Altamira in Para State, looking especially to highlight the policies planned, through a set of official documents, aimed at promoting activity. Methodological procedure was carried out, the survey and document analysis, as well as research and analysis of the literature that deals with the production of tourism policies for the Amazon state of Para, and therefore the Altamira. Made the organization and systematization of data collected shows up policies for tourism development in Altamira and its special relationship with the discourse of sustainable development emerges where policies to encourage ecotourism.
\end{abstract}

KEYWORDS: Tourism Policies; Development; Ecotourism; Amazon; Altamira.

Página 850 Revista Brasileira de Ecoturismo, São Paulo, v.6, n.5, nov 20 I3-jan 20 I4, pp.850-86I.

Sociedade Brasileira de Ecoturismo. Rua Dona Ana, I38, Vila Mariana, São Paulo, SP - Brasil. E-mail: rbecotur@sbecotur.org.br; Tel. (55-II) 99196-7685. 
Políticas públicas, atividade turística e estratégias de desenvolvimento: uma abordagem sobre o turismo em Altamira (PA)

\section{Introdução}

De um ponto de vista econômico o fenômeno turístico é responsável por um grande fluxo de capital verificado pelo crescimento desse setor no conjunto da economia mundial. Nesse sentido, emergem práticas de gestão como exemplo de estratégias governamentais, onde ações do Estado são exercidas para implementação e desenvolvimento da atividade.

Essas ações se constituem em políticas públicas de turismo entendidas como conjunto de intenções e estratégias e/ou ações deliberadas, no âmbito do poder publico, com o objetivo de promover o desenvolvimento das atividades turísticas em um dado território (CRUZ, 2000). São essas políticas públicas, que vêm sendo implementadas nas diversas escalas do espaço geográfico, incentivando-se o turismo como estratégia para o desenvolvimento.

Deste modo, tem sido pensadas e implementadas ações de incentivo ao desenvolvimento da atividade em Altamira no estado do Pará. No contexto atual, o turismo também é visualizado com uma importante estratégia de gestão em nos municípios amazônicos. Isso se explica, também, pelo crescimento da atividade na região que apresenta uma das atratividades principais para o setor, a natureza. Nestes termos, buscar-se-á neste trabalho abordar o turismo em Altamira, evidenciando a atividade nesse município da região do Médio Xingu, a partir da análise das políticas de incremento à atividade.

$\mathrm{O}$ trabalho está estruturado em dois momentos. No primeiro é situado o turismo como política pública e sua utilização como estratégia de desenvolvimento. Em seguida, evidencia-se o turismo pensado para Altamira, através de documentos oficiais, Plano de Desenvolvimento do Turismo no Pará- PDT-PA, Plano Diretor do Município, Plano de Turismo Municipal, dentre outros, e sua relação especial com o paradigma do desenvolvimento sustentável.

Portanto, nosso argumento principal é que a partir da utilização do turismo como estratégia de gestão para o desenvolvimento, através das políticas para o setor, - discurso do desenvolvimento sustentável, está presente nas políticas (consubstanciadas em documentos) de desenvolvimento do turismo em Altamira.

\section{Políticas públicas, turismo e desenvolvimento}

É a crescente relevância econômica do turismo o motivo principal que leva à necessidade de intervenção através de seu planejamento. Segundo Rodrigues (1997), em vista de seus importantes efeitos econômicos e sociais, o turismo, organizado e planejado, é poderoso instrumento de aceleração ou complementação do processo de desenvolvimento.

De acordo com Hall (2001) são cinco as áreas de envolvimento do Estado em relação ao seu papel na promoção dessa atividade: coordenação, planejamento, legislação, regulamentação, empreendimentos e incentivos. Do mesmo modo, para

Página 85I Revista Brasileira de Ecoturismo, São Paulo, v.6, n.5, nov 20I3-jan 20 I4, pp.850-86I. 
Rodrigues (1997) o Estado pode agir como firma e produzir bens e serviços, tais como hotéis, centros de convenções, marinas e terminais turísticos. Torna-se, desse modo, planejador e promotor territorial: a terceira fonte de turistificação dos lugares nos termos de Knafou (2001).

Nesse sentido, a ação indutora do Estado visando ao desenvolvimento, a partir de medidas de fomento ao turismo, tornou-se uma das principais iniciativas do governo nos últimos anos no Brasil, configurando-se todo um sistema de ações e de objetos (SANTOS, 2004) expressos através das políticas públicas e dos equipamentos e infraestrutura. Emergem, assim, as políticas territoriais de turismo.

Conforme Cruz (2000) é através da política setorial e dos programas e planos a ela vinculados que a administração pública dá visibilidade a seu projeto de governo para um dado setor da vida social. Ainda para a autora, a política pública de turismo deveria, teoricamente, estar consubstanciada em um "documento" público, que reunisse o pensamento do(s) poder(es) público(s), em seus vários níveis, com relação à organização do setor turístico em um dado território.

Desse modo, o planejamento da atividade é indispensável para o sucesso no alcance dos objetivos. Entretanto,

[...] como o turismo acontece primeiramente nos lugares, na grande parte das vezes, de forma espontânea, seu planejamento pode ser prejudicado não apenas por uma suposta incapacidade administrativa da gestão pública de pensar o futuro, mas inclusive por uma miopia crônica que lhes impede de enxergar até mesmo o presente (CRUZ, 2000, p.4).

Destaca-se, portanto, a importância do planejamento dessa atividade e das políticas resultantes, pois é necessário que ele esteja inserido nas políticas públicas governamentais. Por meio destas o governo pode tanto definir responsabilidades quanto também dar visibilidade a seu projeto e aos programas e planos a ele atrelados para um dado setor da administração pública (CRUZ, 2001).

O descaso com o planejamento territorial, ignorando-se as especificidades regionais, desconsiderando-se o lugar, não se preocupando com a ordenação e a gestão do território a partir das suas especificidades, expressa a falta de visão de planejamento pela estruturação das formas e ações em nível espacial (RODRIGUES, 2001). Assim, o modo como se dá a apropriação de uma determinada parte do espaço geográfico pelo turismo depende da política pública que se leva a cabo no lugar, sendo que compete à política pública de turismo o estabelecimento de metas e diretrizes que orientem o desenvolvimento sócio-espacial da atividade (CRUZ, 2000).

Ressalta-se ainda que as políticas de turismo, estabelecidas pelo poder público, devem contemplar os vários atores sociais envolvidos, ou seja, as diversas coletividades, para que ocorra um desenvolvimento que se coloque para além da 
Políticas públicas, atividade turística e estratégias de desenvolvimento: uma abordagem sobre o turismo em Altamira (PA)

geração de renda e emprego, que gere um processo de justiça social e autonomia dos atores envolvidos no desenvolvimento da atividade, sendo utilizada, assim, como estratégia de gestão do território para o desenvolvimento sócio-espacial nos termos de Souza (1996).

Esse é o grande desafio que se coloca tornar o turismo um propiciador de desenvolvimento; entretanto, isto precisa ser construído considerando que não basta somente um desenvolvimento econômico. É preciso refletir sobre a possibilidade de utilização da atividade turística como estratégia de desenvolvimento em sentido amplo.

Entretanto, o turismo é visto recorrentemente pelo seu destaque econômico. Desse modo, passou a ser utilizado como estratégia para o desenvolvimento econômico na Amazônia, através de programas e planos que incentivam o crescimento do setor em nível estadual e municipal como veremos considerando o caso de Altamira.

\section{O turismo pensado para Altamira nos planos estaduais e municipais}

A formação territorial de Altamira inseri-se no processo de ocupação e povoamento do rio Xingu, em função das ações realizadas pelos religiosos no século XVII. O jesuíta Roque Hunderfund, que em meados do século XVII ultrapassou o trecho encachoeirado da Volta Grande no rio Xingu, fundou uma missão próxima ao Igarapé de Panelas. Nesta missão funcionava um aldeamento para a catequese de silvícolas, fato que deu origem a Altamira que primeiramente fez parte do município de Souzel (UMBUZEIRO, 2012).

Sua fundação oficial data de 1911, entretanto, os primeiros núcleos populacionais surgiram ainda no final do século XIX no contexto da exploração da borracha, ocorrendo um período de apogeu em Altamira em função das atividades vinculadas à essa produção, constituindo seu principal quadro econômico, dentro do contexto da economia extrativa que predominou na região amazônica até a década de 1960.Entre as principais atividades econômicas atuais destacam-se a agricultura e a pecuária, além do setor extrativo vegetal, mais precisamente a atividade vinculada à exploração madeireira (ALTAMIRA, 2012).

A partir da década de 1950 são desencadeadas transformações na organização espacial da Amazônia, em função da abertura das estradas e rodovias e a expansão das novas atividades capitalistas, que incorporam principalmente algumas áreas ricas em recurso naturais na lógica da ocupação. Nestes termos, durante os últimos 50 anos, Altamira tem visto um enorme crescimento populacional e ondas migratórias, onde o marco desse processo foi a construção da rodovia Transamazônica na década de 1970.

Atualmente existe uma grande expectativa com relação à instalação da UHE de Belo Monte. Esse grande projeto está cercado de polêmicas em função das repercussões socioambientais que já estão sendo implementadas. Apesar disso, os defensores do projeto vislumbram no empreendimento uma possibilidade de maior

Página 853 Revista Brasileira de Ecoturismo, São Paulo, v.6, n.5, nov 20 I3-jan 20।4, pp.850-86I. 
dinamismo para os setores produtivos da região, especialmente para Altamira, já que as políticas de desenvolvimento em âmbito municipal direta ou indiretamente sofrem a influência da instalação do empreendimento.

Nesse contexto, um dos setores que podem ser incrementados, a partir do empreendimento, é o turismo. Isto porque por ser um projeto de infraestrutura de grande porte, este possui elevado potencial de interesse e atratividade para o turismo. Por outro lado, a formação do lago, resultante da construção da hidrelétrica, implicará no desaparecimento de algumas praias, prejudicando assim, não só o turismo, mas principalmente o lazer dos moradores de Altamira (ALTAMIRA, 2008).

A atividade turística vem sendo incentiva por meio de planos em nível em nível estadual e municipal. No Estado do Pará, o turismo tornou-se uma das ações prioritárias de gestão. Hoje, além das atividades de mineração e agropecuária, o governo estadual busca consolidar o desenvolvimento do ecoturismo como mecanismo de expansão da atividade (FIGUEIREDO, 1999). Este segmento surge como uma alternativa possível, como uma modalidade de turismo que congregaria exploração com proteção da natureza, tornando-se apropriada no contexto do desenvolvimento sustentável, que marca a expansão da fronteira tecno-ecológica nos termos de Becker (2006).

Os Estados e Municípios na Amazônia passam a incentivar o turismo de acordo com as diretrizes apontadas por documentos elaborados em âmbito federal a exemplo do Plano de Turismo da Amazônia (PTA) e Programa para o Desenvolvimento do Ecoturismo na Amazônia Legal (PROECOTUR) (COELHO, 1999). Nesse contexto, os governos dão maior ênfase ao turismo, subsidiando-o e incluindo-o definitivamente nas políticas públicas, tornando-o parte integrante da máquina governamental (HALL, 2001).

No Estado do Pará, através de seu órgão representativo de turismo, a PARATUR, foi elaborado em 2001 o Plano de Desenvolvimento Turístico (PDT-PA), documento que congrega as diretrizes gerais para o turismo no Estado. Dentro do referido plano os objetivos propostos têm como intenção promover o turismo aliando a sustentabilidade da região amazônica à competitividade (SERRA, 2007). A partir do diagnóstico realizado sobre o turismo no Estado, foram analisados os pontos fortes e fracos para contribuir ou dificultar o desenvolvimento do turismo, e, principalmente, as oportunidades competitivas por cada polo turístico em que foi dividido o Estado (Figura 1).

A partir do documento elaborado foram estabelecidas as principais estratégias para cada polo e indicados os negócios priorizados por mercado geográfico (prioridade alta, média ou baixa). Para o polo Xingu, onde se insere Altamira, as estratégias e mercados são vistos no Quadro 1. 
Políticas públicas, atividade turística e estratégias de desenvolvimento: uma abordagem sobre o turismo em Altamira (PA)

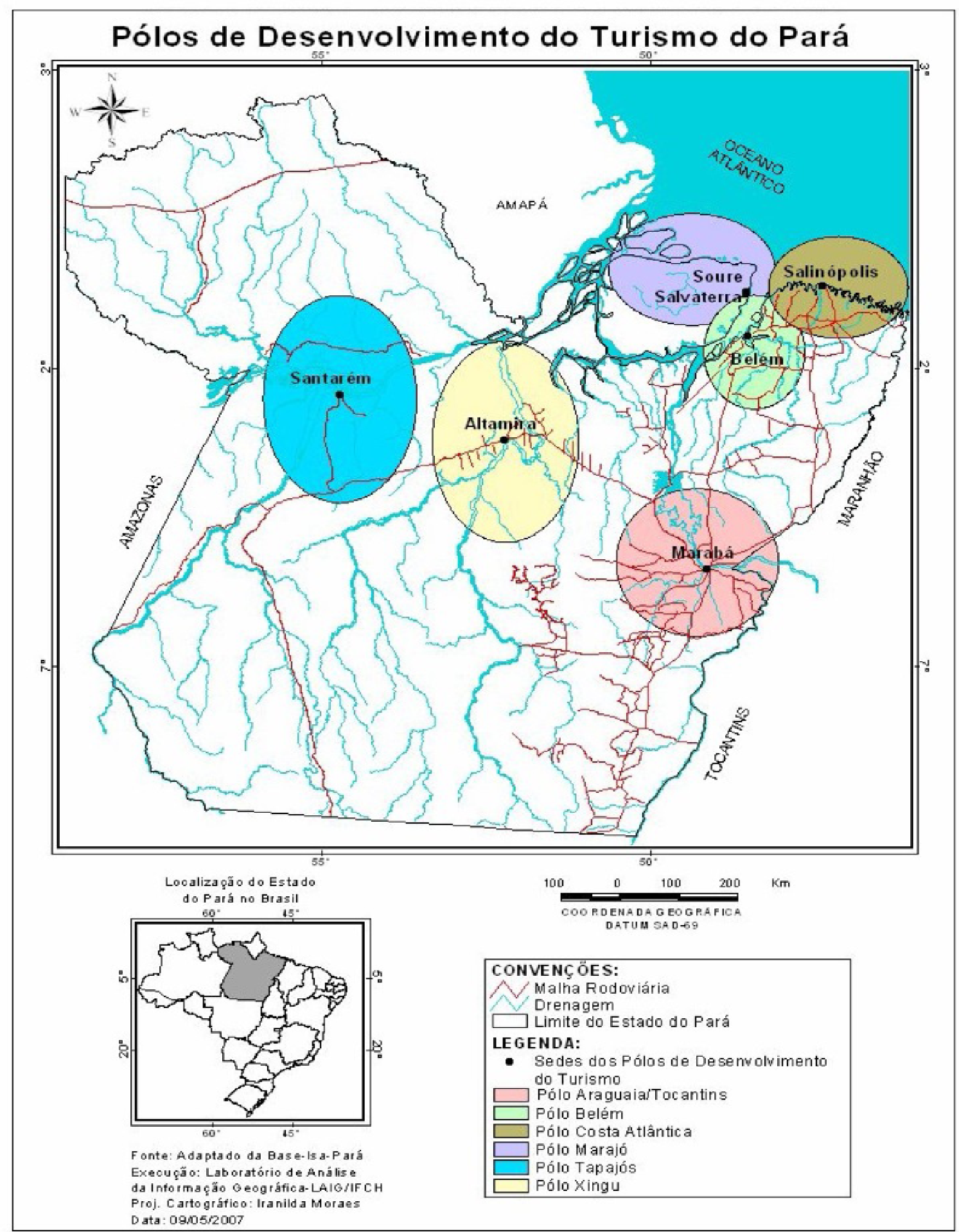

Figura 1: Mapa dos Polos de Desenvolvimento do turismo do Pará. Fonte: Serra (2007).

Figure 1: Map of the Centers for Tourism Development of Pará. Source: Serra (2007). 
Quadro 1: Estratégias de produto/mercado Polo Xingu.

Table 1: Product strategies/marketing Polo Xingu.

\begin{tabular}{|l|c|c|c|c|}
\hline \multirow{2}{*}{ Negócios/Mercados } & \multicolumn{5}{|c|}{ Mercados geográficos } \\
\cline { 2 - 5 } Ecoturismo & Doméstica & Regional & Nacional & Internacional \\
\hline Turismo de aventuras & - & - & & \\
\hline Turismo de interesse especial & - & - & & \\
\hline Pesca esportiva & $\bullet$ & - & & \\
\hline
\end{tabular}

Prioridade alta

Fonte: Pará (2001). Source: Pará (2001).

Dentre outros destaques, verifica-se a ênfase dada ao ecoturismo como a modalidade viável ao Pólo Xingu e, por conseguinte, à Altamira, fundamentando as ações de desenvolvimento da atividade turística no polo por se constituir num dos segmentos mais viáveis no paradigma do desenvolvimento sustentável tão em voga na Amazônia, estando presente em quase todos os programas e projetos de desenvolvimento do turismo na região (BECKER, 2006).

O turismo de aventura e a pesca esportiva complementam os negócios prioritários que deveriam ser desenvolvidos no polo. Este último é visto como setor de grande potencial, tendo sido explorado com mais intensidade em Altamira através do incentivo a eventos como o Torneio de Pesca do Tucunaré e o Torneio de Pesca do Pacu de Seringa. Além disso, o Governo do Estado do Pará implantou no Polo Xingu um sítio pesqueiro, nele somente a prática da pesca esportiva é permitida, fazendo parte do roteiro "Pesque Xingu" as cidades de Altamira, Brasil Novo e Vitória do Xingu.

Dentro da esfera pública municipal o turismo passou a ser tratado especialmente a partir da década de 1990. A atividade é mencionada na Lei Orgânica do Município como um setor econômico de desenvolvimento (ALTAMIRA, 1990). Além disso, este é o momento que a atividade ganha destaque no contexto da Amazônia, entrando na pauta de discussão políticas públicas para o setor.

De acordo com Hall (2001), a elaboração de políticas para o turismo passou a ser adotada por órgãos do governo em todos os níveis, colocando o turismo como estratégia importante para a geração de emprego e renda. O maior tratamento dado ao turismo no sentido de promover seu desenvolvimento torna-se, então, uma tônica, tanto nas políticas dos governos estaduais como municipais já que atividade é vista como uma estratégia de desenvolvimento, capaz de gerar benefícios econômicos e 
Políticas públicas, atividade turística e estratégias de desenvolvimento: uma abordagem sobre o turismo em Altamira (PA)

sociais e para ele é dada atenção especial através da criação de secretarias, como acontece em Altamira, onde o turismo está presente na estrutura do governo municipal, como Coordenadoria de Turismo, integrada à Secretaria Municipal de Gestão do Meio Ambiente e Turismo.

Inicialmente a Divisão de Turismo estava integrada à Secretaria Municipal de Agricultura, Abastecimento e Turismo. A partir de 2001 passou a fazer parte da Secretaria Municipal de Gestão do Meio Ambiente e Turismo e, finalmente, a partir de 2010 passou a ser Coordenadoria de Turismo composta por 4 divisões (Divisão de Gestão Turística, Divisão de Financiamento e Promoção de Incentivo no Turismo, Divisão de Estruturação, Articulação e Ordenamento Turístico e Divisão de Programas e Desenvolvimento do Turismo) e 2 departamentos (Departamento de Qualificação e Certificação de Produção Associada ao Turismo e Departamento de Infraestrutura Turística).

O principal documento de turismo existente em âmbito municipal, o Plano Municipal de Turismo, resulta de uma ação realizada em 2008 pela PARATUR (órgão oficial de Turismo do Estado) com o intuito de apontar os principais gargalos existentes e as ações possíveis para explorar o potencial turístico local. Além disso, o Plano Diretor do Município também aponta, na descrição atual do município, a grande potencialidade existente, destacando o rio Xingu como principal atrativo.

A partir da análise dos principais documentos referentes ao turismo no município (Quadro 2) verificamos que o potencial turístico de Altamira é visualizado principalmente para o ecoturismo, pois a existência de rios, destacando-se o Rio Xingu, igarapés, praias e quedas d'água, assim como cavernas e florestas, permitiriam a prática dessa modalidade de turismo.

Seguindo uma tendência, em Altamira, esta modalidade também é utilizada como sinônimo de sustentabilidade, sendo respaldada nos discursos das instituições oficiais de turismo do Estado e do Município através de planos para o setor. Assim, o que se verifica é a perspectiva de desenvolver a atividade, contudo, consideramos importante uma discussão da possibilidade de promover um desenvolvimento para além da questão econômica. Isto porque, na maioria dos casos, o turismo é visto como salvação econômica, o que não é diferente em Altamira.

É preciso analisar que a sociedade é formada por atores sociais diferentes. Além disso, existe a questão da autonomia levantada sobre a atividade, pois se pressupõe que uma coletividade tenha autonomia, disciplinando o turismo conforme seus interesses e suas necessidades. Souza (2002) contribuindo para essa discussão ressalta que a população das áreas receptoras não é homogênea, então, essa autonomia, então, seria de que grupo social? Para Becker (1991), ao nível local, tratando-se de espaços convivenciais, é prioritária para a gestão a participação da população e do saber local na formulação e na execução das estratégias, táticas e técnicas a serem utilizadas. 
Cordovil, J.C.S.; Cebuliski, B.S.P.; Costa, W.L.; Nunes, P.B.

\begin{tabular}{|c|c|c|c|c|}
\hline 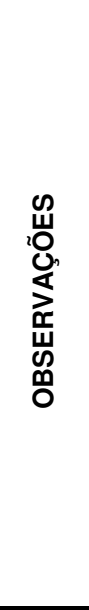 & 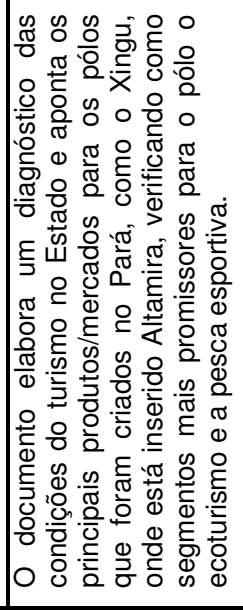 & 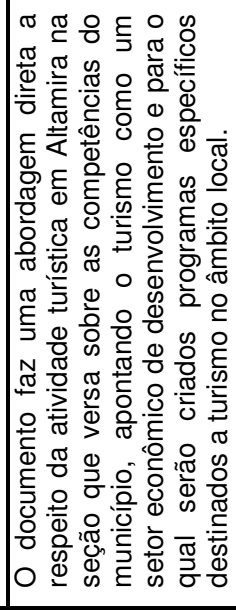 & 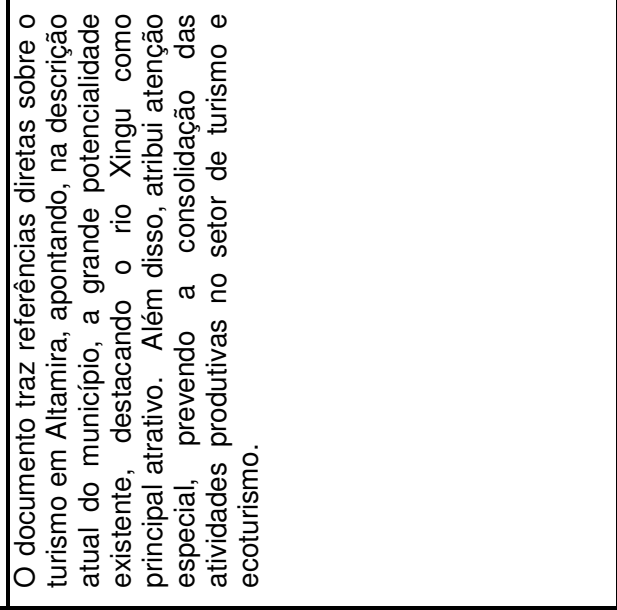 & 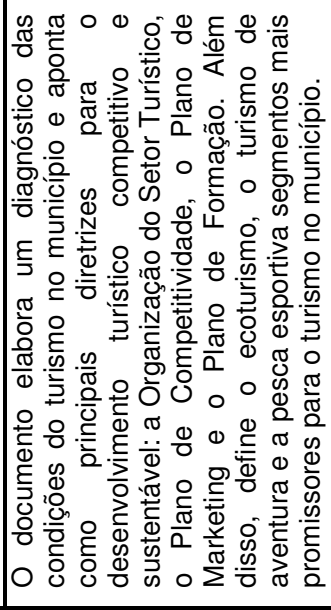 \\
\hline 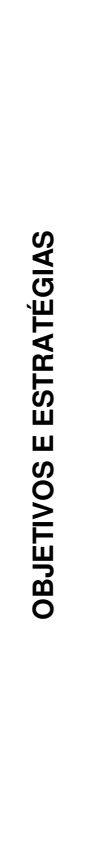 & 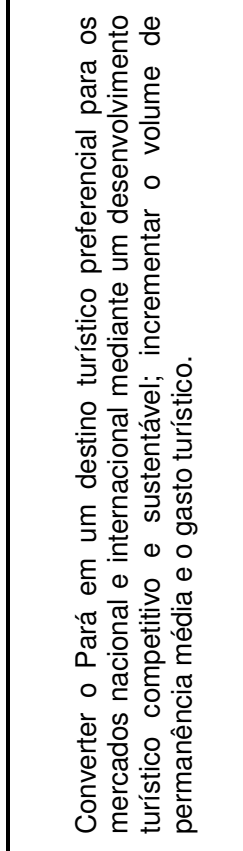 & 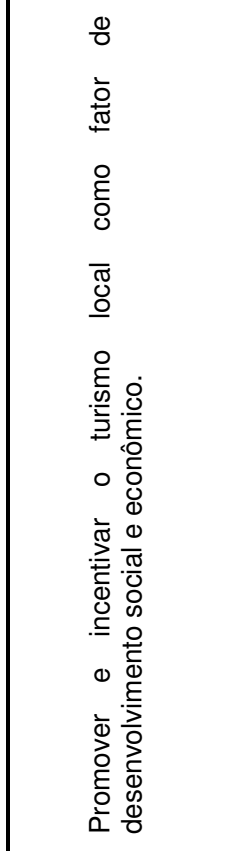 & 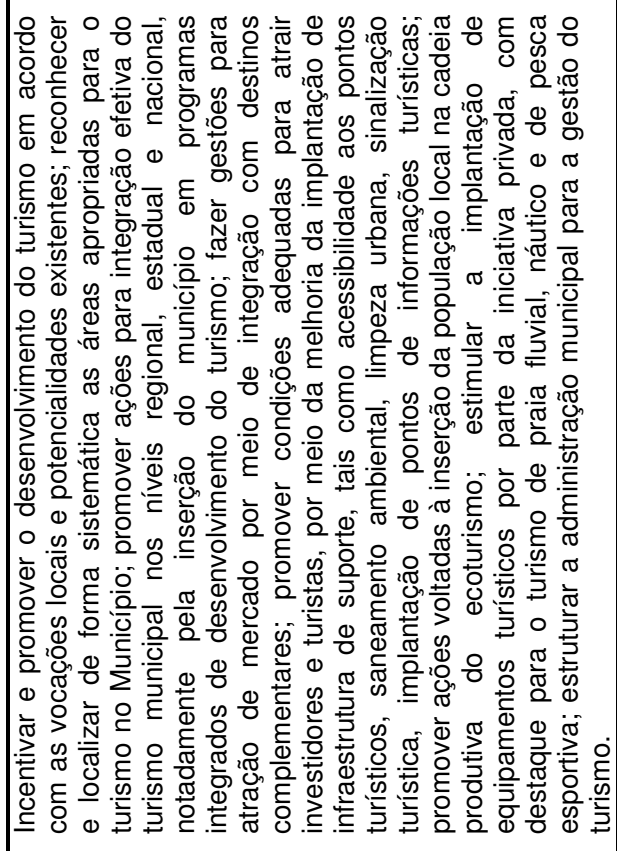 & 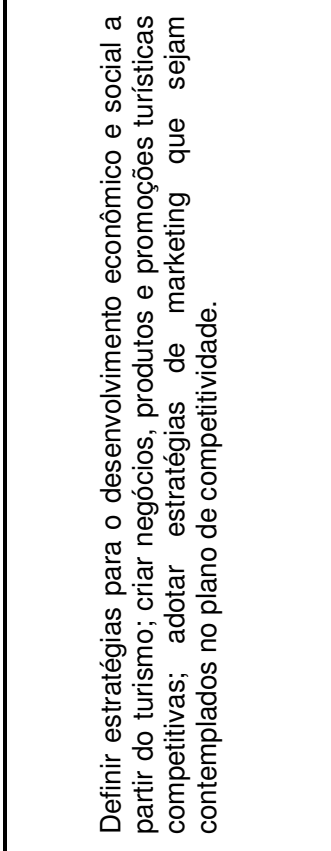 \\
\hline 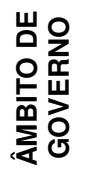 & 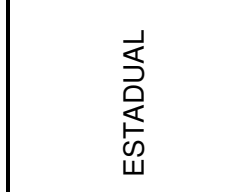 & 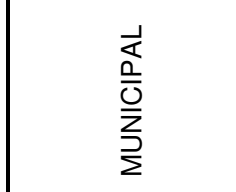 & 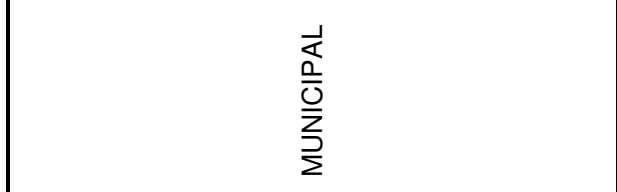 & 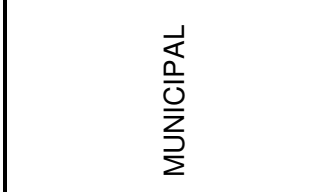 \\
\hline 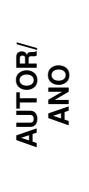 & 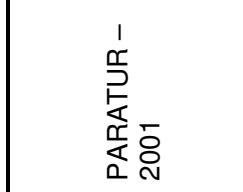 & 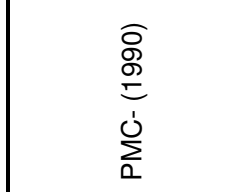 & $\begin{array}{l}\widehat{0} \\
\stackrel{0}{0} \\
\frac{1}{1} \\
\sum_{0}\end{array}$ & $\begin{array}{l}\widehat{\infty} \\
\stackrel{0}{0} \\
\frac{1}{1} \\
\sum_{0}^{1}\end{array}$ \\
\hline 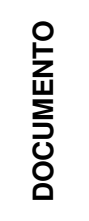 & 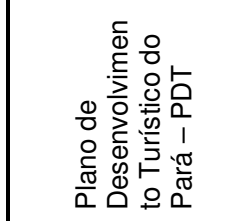 & 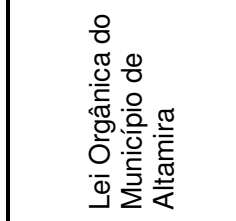 & 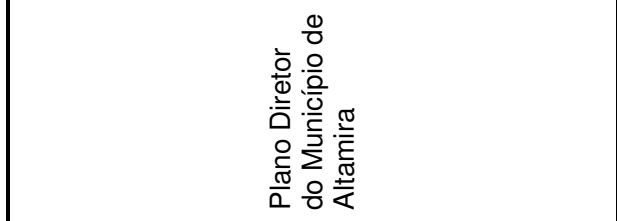 & 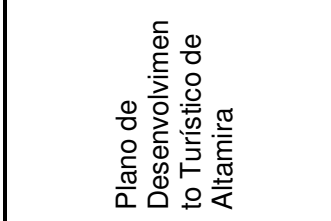 \\
\hline
\end{tabular}


Políticas públicas, atividade turística e estratégias de desenvolvimento: uma abordagem sobre o turismo em Altamira (PA)

Portanto, o grande desafio é a perspectiva de desenvolvimento da atividade de forma sustentável e em bases locais, pensando o turismo como um propiciador de desenvolvimento, um fator de sustentabilidade, mas esta precisa ser construída considerando que não basta somente pensar o desenvolvimento econômico, ou que este não seja somente fundamentado numa abordagem ambientalista. $O$ aproveitamento das potencialidades existentes requer planejamento e a gestão participativa como passos importantes na elaboração e implementação de ações de incentivo ao turismo local.

\section{Considerações finais}

Nas últimas décadas o governo brasileiro passou a conceber, incentivar e implementar políticas de desenvolvimento do turismo nas diversas áreas que compõem o território nacional. Na Amazônia a atividade turística apresenta-se como uma verdadeira frente pioneira (RODRIGUES, 2001) pelas estratégias espaciais voltadas para instalação e desenvolvimento da atividade, onde é proposta como modalidade mais viável o ecoturismo, como forma de aliar estratégia de desenvolvimento à conservação da natureza.

Assim, é cada vez mais forte a tendência dos governos estaduais e municipais, na região, buscarem como estratégia de desenvolvimento a prática de políticas de fomento à atividade turística, principalmente, incentivando a modalidade do ecoturismo, inspirado no discurso do desenvolvimento sustentável.

Esse é o caso de Altamira, onde se verifica o grande interesse de inserir o município nas rotas do turismo sem uma reflexão sobre a pertinência das ações e sobre a perspectiva de desenvolvimento da atividade como possibilidade de promover um desenvolvimento para além da questão ambiental e econômica. Nestes termos, 0 ecoturismo é utilizado como sinônimo de sustentabilidade, e é incorporado nas políticas de gestão pública como um impulsionador do desenvolvimento econômico local, sendo respaldado nos discursos das instituições oficiais.

Desta forma, observa-se que Altamira pode ser considerada um destino turístico porque possui atratividades e potenciais, além de equipamentos e infraestruturas, elementos relevantes para o desenvolvimento da atividade turística. Contudo, é importante que as ações de incentivo ao turismo sejam resultado de discussões e de participação social verificando-se as propostas dos vários setores que veem no turismo uma alternativa para o desenvolvimento.

\section{Referências bibliográficas}

ALTAMIRA. Lei Orgânica Municipal. Altamira, 1990.

ALTAMIRA.Plano diretor do Município de Altamira. Altamira, 2005.

ALTAMIRA. Inventário da Oferta Turística do Município de Altamira. Secretaria Municipal de Gestão do Meio Ambiente e Turismo - Altamira-PA; SEMAT, 2012. 
BECKER, B. Geografia política e gestão do território no limiar do século XXI: uma representação a partir do Brasil. Revista Brasileira de Geografia, Rio de Janeiro, v. 53, n. 3, p. 169-182, jul./set. 1991.

BECKER, B. Amazônia:geopolítica na virada do III milênio. Rio de Janeiro: Garamound, 2006.

CRUZ, R.A. Política de turismo e território. São Paulo: Contexto, 2000. (Coleção Turismo).

CRUZ, R.A. Introdução à geografia e turismo. São Paulo: Roca, 2001.

FIGUEIREDO, S. L.Ecoturismo e desenvolvimento sustentável: alternativa para o desenvolvimento da Amazônia? In: FIGUEIREDO, S. O ecoturismo e a questão ambiental na Amazônia. Belém: NAEA/UFPA, 1999.

HALL, M. Planejamento turístico: políticas, processos relacionamentos. São Paulo: Contexto, 2001.

KNAFOU, R. Turismo e território: para um enfoque científico do turismo. In: RODRIGUES, A.B. Turismo e geografia: reflexões teóricas e enfoques regionais. 3. ed. São Paulo: HUCITEC, 2001. p. 62 - 74.

PARÁ. Governo do Estado. Plano de desenvolvimento do turismo do Estado do Pará (PDT-PA). Belém: Companhia Paraense de Turismo- PARATUR; THRassessoria em turismo hotelaria e recreação, 2001.

RODRIGUES, A.B. Turismo e espaço: rumo a conhecimento interdisciplinar. São Paulo: HUCITEC, 1997.

RODRIGUES, A.B. Turismo e geografia: reflexões teóricas e enfoques regionais. 3. ed. São Paulo: HUCITEC, 2001.

SANTOS, M. Natureza do espaço: técnica e tempo, razão e emoção. São Paulo: 4. ed. EDUSP, 2004.

SERRA, H. A concepção de turismo e de sua espacialidade no plano de desenvolvimento de turismo do Pará-PDT, 2007. Dissertação (Mestrado em Geografia)- Instituto de Filosofia e Ciências humanas, Universidade Federal do Pará.

SOUZA, M.L. A teorização sobre o desenvolvimento em época de fadiga teórica, ou: sobre a necessidade de uma teoria aberta do desenvolvimento sócio-espacial. Revista Território, v. 1, n. 1, p. 5-22, jul/dez, 1996.

SOUZA, M.L. Como pode o turismo contribuir para o desenvolvimento local? In: RODRIGUES, A.B. Turismo e desenvolvimento local. 3. ed. São Paulo: HUCITEC, 2002.

UMBUZEIRO, A.U.B. Altamira e sua história. 4 ed. Belém: Ponto Press, 2012. 
Políticas públicas, atividade turística e estratégias de desenvolvimento: uma abordagem sobre o turismo em Altamira (PA)

José Carlos da Silva Cordovil: Universidade Federal do Pará, Belém, PA, Brasil.

Email: jccordovil@ig.com.br

Link para o currículo Lattes: http://lattes.cnpq.br/6305366608922811

Bruna Suelen Pereira Cebuliski: Universidade Federal do Oeste do Pará, Santarém, PA, Brasil.

Email: bruna.tur@hotmail.com

Link para o currículo Lattes: http://lattes.cnpq.br/0732205482320529

Wagner Lima Costa: Universidade Federal do Pará, Belém, PA, Brasil.

Email:wa.wesley.geo@gmail.com

Link para o currículo Lattes: http://lattes.cnpq.br/9945148825914557

Patrícia Barbosa Nunes: Universidade Federal do Pará, Belém, PA, Brasil.

Email: patricia_bn@hotmail.com

Link para o currículo Lattes: http://lattes.cnpq.br/6034018840202286

Data de submissão: 31 de maio de 2012

Data de recebimento de correções: 16 de julho de 2013

Data do aceite: 20 de setembro de 2013

Avaliado anonimamente 